\title{
SEPSIS: FROM BENCH TO BEDSIDE
}

Eliézer Silva, Rogério Da Hora Passos, Maurício Beller Ferri, Luiz Francisco

Poli de Figueiredo

Silva E, Passos RDH, Ferri MB, Poli de Figueiredo LF. Sepsis: from bench to bedside. Clinics. 2008;63(1):109-20.

Sepsis is a syndrome related to severe infections. It is defined as the systemic host response to microorganisms in previously sterile tissues and is characterized by end-organ dysfunction away from the primary site of infection. The normal host response to infection is complex and aims to identify and control pathogen invasion, as well as to start immediate tissue repair. Both the cellular and humoral immune systems are activated, giving rise to both anti-inflammatory and proinflammatory responses. The chain of events that leads to sepsis is derived from the exacerbation of these mechanisms, promoting massive liberation of mediators and the progression of multiple organ dysfunction. Despite increasing knowledge about the pathophysiological pathways and processes involved in sepsis, morbidity and mortality remain unacceptably high. A large number of immunomodulatory agents have been studied in experimental and clinical settings in an attempt to find an efficacious anti-inflammatory drug that reduces mortality. Even though preclinical results had been promising, the vast majority of these trials actually showed little success in reducing the overwhelmingly high mortality rate of septic shock patients as compared with that of other critically ill intensive care unit patients. Clinical management usually begins with prompt recognition, determination of the probable infection site, early administration of antibiotics, and resuscitation protocols based on "early-goal" directed therapy. In this review, we address the research efforts that have been targeting risk factor identification, including genetics, pathophysiological mechanisms and strategies to recognize and treat these patients as early as possible.

KEYWORDS: Sepsis. Shock. Infection. Organ Dysfunction. Organ Failure.

\section{INTRODUCTION}

The word sepsis is derived from the Greek term for rotten or "to make putrid". Sepsis, defined as the systemic host response to microorganisms in previously sterile tissues, is a syndrome related to severe infections and is characterized by end-organ dysfunction away from the primary site of infection. To meet the definition of sepsis, patients need to satisfy at least two of the Systemic Inflammatory Response Syndrome (SIRS) criteria in association with having a suspected or confirmed infection. ${ }^{1,2,3,4,5}$ The severity and mortality increase when this condition is complicated by predefined organ dysfunction (severe sepsis) and cardiovascular collapse (septic shock). ${ }^{6}$

Research Division, Heart Institute (InCor), Hospital das Clínicas, Faculdade de Medicina da Universidade de São Paulo - São Paulo/SP, Brazil. elisilva@uol.com.br

Received for publication on August 24, 2007. Accepted for publication on September 14, 2007.
The normal host response to infection is complex, aiming to both identify and control pathogen invasion and start immediate tissue repair. Both the cellular and humoral immune systems are activated, giving rise to anti-inflammatory and proinflammatory responses. Exacerbating these mechanisms can cause a chain of events that leads to sepsis, promoting massive liberation of mediators and the progression of multiple organ dysfunction. ${ }^{7}$

Morbidity and mortality remain unacceptably high despite increasing knowledge about the pathophysiological pathways and processes involved in sepsis. It still is one of the most prevalent causes of intensive care units (ICU) morbidity and mortality worldwide. ${ }^{1,8}$ More than 750,000 sepsis cases occur in the United States every year, leading to approximately 220,000 deaths. ${ }^{9,10}$ Consistent data on the incidence, outcome and costs of sepsis patients in Brazil and Latin America are scarce. However, a recent Brazilian study showed that up to $25 \%$ of ICU patients will meet sepsis diagnostic criteria during an ICU stay. ${ }^{11}$ Even with the 
best treatment available, the mortality rates of septic shock could be as high as $50 \% \%^{1,6,8,9,11}$ or up to $75 \%$ on longer follow-ups. ${ }^{12}$

In an attempt to find an efficacious anti-inflammatory drug that reduces mortality, a large number of immunomodulatory agents have been studied in experimental and clinical settings. However, the vast majority of these trials showed little success in reducing the overwhelmingly high mortality rates of septic shock patients as compared to those other critically ill ICU patients, ${ }^{9,13,14,15}$ despite promising preclinical results. Clinical management usually begins with prompt recognition, determination of the probable infection site, early administration of antibiotics, and resuscitation protocols based on "early-goal" directed therapy.,10 In this review, we address the research efforts that have been targeting both risk factor identification, including genetics, pathophysiological mechanisms and strategies to recognize and treat these patients as early as possible.

\section{Definitions}

The syndrome currently known as sepsis has had many definitions over the years. ${ }^{2}$ In 1991, a consensus conference organized by the American College of Chest Physicians and the Society of Critical Care Medicine clinically defined the terms SIRS, sepsis, severe sepsis and septic shock (Table 1). ${ }^{1,2,3,4}$ Even though the definition has high sensitivity and low specificity, it has been helpful in improving patient care, enrollment in clinical trials and communication between ICUs.

A second conference held in 2001 attempted to refine the definitions, increase specificity by emphasizing prompt recognition and add a list of common symptoms and signs of sepsis. ${ }^{2,3,5,10}$ The current definitions are as follows:

- Infection: pathologic process caused by invasion of normally sterile tissue, fluid or body cavity by pathogenic or potentially pathogenic microorganisms.

- Sepsis: documented or suspected infection associated with any of the systemic inflammatory syndrome signs.

- Severe Sepsis: sepsis complicated by pre-defined organ dysfunction.
Table 1 - Sepsis definitions

1. Systemic Inflammatory Response Syndrome (SIRS). Two or more of the following: a) temperature (core) $>38.3^{\circ} \mathrm{C}$ or $\left\langle 36^{\circ} \mathrm{C}\right.$; b) heart rate $>$ 90 beats/min; c) respiratory rate $>20$ breaths $/ \mathrm{min}, \mathrm{PaCO}_{2}<32 \mathrm{~mm} \mathrm{Hg}$ or need for mechanical ventilation; d) WBC count $>12.000 / \mathrm{mm}^{3}$ or $<$ $4.000 / \mathrm{mm}^{3}$ or $>10 \%$ immature forms (bands).

2. Sepsis is defined as SIRS associated with suspected or confirmed infection. Positive blood cultures are not necessary ${ }^{16}$.

3. Severe sepsis is sepsis complicated by a predefined organ dysfunction

4. Septic shock is cardiovascular collapse related to severe sepsis despite adequate fluid resuscitation. Hypotension is: systolic blood pressure $(\mathrm{SBP})<90 \mathrm{~mm} \mathrm{Hg}$, mean arterial pressure (MAP) $<65 \mathrm{~mm} \mathrm{Hg}$ or a reduction of $>40 \mathrm{~mm} \mathrm{Hg}$ on baseline SBP.

5. Organ dysfunction criteria are a) hypoxemia $\left(\mathrm{PaO}_{2} / \mathrm{FiO}_{2}\right.$ ratio $\left.<300\right)$; b $)$ acute oliguria (urine output $<0.5 \mathrm{ml} / \mathrm{kg} / \mathrm{h}$ for $2 \mathrm{~h}$ ) or creatinine $>2.0$ $\mathrm{mg} / \mathrm{dL}$; c) coagulopathy (platelet count $<100.000$, INR $>1.5$ or pTTa $>$ $60 \mathrm{~s}$ ); d) ileus; e) plasma bilirubin $>4 \mathrm{mg} / \mathrm{dL})^{1,2,5,10}$.

- Septic Shock: sepsis-induced acute circulatory failure characterized by persistent arterial hypotension despite adequate volume administration and not explained by causes other than sepsis.

Besides refining the diagnostic definitions, the 2001 consensus conference brought new insight into sepsis staging, with the aim of better characterizing disease severity. The PIRO concept was then introduced (Table 2) with the idea that these factors would have relevant impact on sepsis development and outcome. . $^{25,10}$

\section{EPIDEMIOLOGY}

Sepsis has been recognized as a major public health problem in population-based and ICU-based epidemiological studies. Two studies have reported the sepsis incidence in the United States $8,9,11,13,14$. Briefly, the methodology used by these reports is primarily based on the International Classification of Diseases, Ninth Revision, Clinical Modification (ICD-9-CM) codes for principal hospital discharge diagnosis. The databases are linked with state and national population data from the US Census for the same year to generate population-based incidence rates. In order to iden-

Table 2 - PIRO concept

\begin{tabular}{lll}
\hline & Clinical & Other tests \\
\hline P (predisposition) & Age, alcohol abuse, steroid or immunosuppressive therapy & Immunologic monitoring, genetic factors \\
I (infection) & Site-specific (e.g., pneumonia, peritonitis) & X-rays, CT scan, bacteriology \\
R (response) & Malaise, temperature, heart rate, respiratory rate & WBC, CRP, PCT, modified APTT \\
O (organ dysfunction) & Arterial pressure, urine output, Glasgow coma score & PaO $_{2} /$ FIO, creatinine, bilirubin, platelets \\
\hline
\end{tabular}

APTT: Aactivated partial thromboplastin time; CRP: C-reactive protein; CT: Computed tomography; PCT: Procalcitonin; WBC: White blood cell count Modified from: Vincent JL, Abraham E. The last 100 years of sepsis. Am J Resp Crit Care Med. 2006. 173:256-263. 
tify cases of severe sepsis, the authors selected all cases with ICD-9 for bacterial or fungal infection and a diagnosis of acute organ dysfunction. Then, the authors compared those patients selected by ICD-9 with the standard clinical criteria for the definitions of severe sepsis ${ }^{9}$ and sepsis. ${ }^{13}$ Martin et al. ${ }^{13}$ estimated the incidence of sepsis in the US as 240 cases per 100,000 people, and Angus et al. ${ }^{9}$ reported 300 cases of severe sepsis per 100,000 people. The inicidence was projected to increase by $1.5 \%$ per annum. The mortality rate reported in these studies was also similar, ranging from $17.9 \%$ for sepsis ${ }^{13}$ to $28.6 \%$ for severe sepsis. ${ }^{9}$ These numbers translate into approximately 750,000 new episodes of severe sepsis, with an annual mortality rate of $220,000(29 \%)$ in the US. It is the tenth most common cause of death in the US, more so even than Acquired Immune Deficiency Syndrome, breast cancer, colon cancer and a first episode of acute myocardium infarction. ${ }^{9,13}$ A French study found that septic shock was the reason for ICU admission in $8.4 \%$ of cases, with a mortality rate of $60 \% .{ }^{14}$ Recently, "Sepsis Occurrence in Acutely Ill Patients (SOAP)" in Europe reported more than 35\% of ICU patients meet sepsis criteria during their ICU stay, with a mortality rate of $27 \% .{ }^{17}$

Silva et al., in the "Brazilian Sepsis Epidemiological Study (BASES study)", ${ }^{11}$ evaluated 1383 consecutive patients in 5 ICUs of tertiary care hospitals distributed over two different regions of the country. They collected daily data on SIRS, sepsis, severe sepsis and septic shock. The median age was 65.2 years-old, and the overall 28-day mortality rate was $21.8 \%$. The incidence density for sepsis, severe sepsis and septic shock were 61.4, 35.6 and 30.0 per 1000 patient-days, respectively. The mortality rates were $24.3 \%$ (SIRS), $34.7 \%$ (sepsis), $47.3 \%$ (severe sepsis) and $52.2 \%$ (septic shock). The respiratory tract was the most common source of infection., ${ }^{8,11}$ This study also showed that there are important regional differences in mortality rates, as well as differences related to the type of hospital administration (public or private). This was accounted for by the fact that Brazil is a continental country with a heterogeneous population and unequal access to health care facilities; thus, social factors may play a more significant role in determining infection patterns and mortality of septic patients. These findings suggest that issues related to the care of septic patients need to be discussed by the whole society. ${ }^{11}$

The recent microbiological patterns of infections that cause septic shock and severe sepsis have changed significantly. Gram-negative bacteria used to be the most frequent germs involved in the pathogenesis of these syndromes. However, Gram-positive bacteria are currently as common as Gram-negative, and fungi are also responsible for a large portion of infections. It is not possible to isolate a patho- gen in about a third of sepsis episodes; in some patients, it is difficult to obtain material for culture. Cultures are often not positive after the initiation of antibiotics. ${ }^{2,8,9,13,14}$

Upward trends in sepsis incidence and patient survival are consistent in the medical literature; however, more people are exposed every year, and the total number of deaths is actually increasing. Patients who have met diagnostic criteria for severe sepsis and septic shock have higher overall mortality rates than other critically ill patients.

\section{PATHOPHYSIOLOGY}

Sepsis describes a complex clinical syndrome that develops when the initial, appropriate host response to an infection becomes amplified and then dysregulated. Determining the structural components of the bacteria that are responsible for initiating the septic process has been important, not only in understanding the underlying mechanisms, but also in identifying potential therapeutic targets. These bacterial motifs, which are recognized by the innate immune system, have been called pathogen-associated molecular patterns (PAMPs), although it might be more accurate to call them microorganism-associated molecular patterns as it is by no means clear how the host distinguishes between signals from pathogens and commensals. ${ }^{18,19}$ In Gram-negative bacteria, lipopolysaccharide (LPS; known also as endotoxin) plays a dominant role. LPS is embedded in the outer membrane, and the lipid A portion of the molecule anchors LPS in the bacterial cell wall. Conformational changes of LPS seem to correlate with its ability to activate host cell membranes. There is no endotoxin in Gram-positive bacteria, but an important feature is the production of potent exotoxins. These Grampositive exotoxins are of great interest because they exhibit the properties of superantigens, that is, they are able to bind promiscuously to major histocompatibility complex class II and a restricted repertoire of T-lymphocyte receptor (TCR) $\mathrm{Vb}$ domains. In so doing, they cause massive T-cell activation and release of pro-inflammatory lymphokines. The best known examples are toxic shock syndrome caused by toxic shock syndrome toxin-1 (TSST-1)-producing strains of Staphylococcus aureus and the pyrogenic exotoxins from Streptococcus pyogenes. Peptidoglycan and lipoteichoic acid from the gram-positive cell walls can bind to cell-surface receptors and are pro-inflammatory, although they are much less active on a weight-for-weight basis than LPS. Their role in the pathogenesis of clinical sepsis remains uncertain. ${ }^{20,21,22}$

\section{Host recognition of microbial components}

The inability to identify an 'LPS receptor' was for many years a barrier to understanding how Gram-negative bac- 
teria initiate the septic response; activation of host cell is dependent on the presence of LPS-binding protein (LBP) and the opsonic receptor CD14. Although CD14 was originally identified as the essential co-receptor that mediated LPS activation of monocytes, subsequent work has shown that it also participates in the activation by Gram-positive cell wall components, such as peptidoglycan, mediates macrophage apoptosis and is important in shuttling LPS between serum proteins that have the capacity to bind LPS, such as LBP and serum lipoproteins..$^{23,33}$

Although the discovery of CD14 represented a significant step forward in understanding host responses to LPS, the fact that mCD14 had no intracellular tail meant that it remained unclear how ligation of the LPS-LBP complex led to cellular activation. This uncertainty was resolved by the discovery of the family of Toll-like receptors (TLRs). The TLRs have an intracellular domain that is homologous with the IL-1 and IL-18 receptors. Adapter proteins facilitate binding to IL-1 receptor-associated kinase, which in turn induces TNF receptor-associated factor-6, leading to nuclear translocation of nuclear factor- $\kappa \mathrm{B}(\mathrm{NF}-\kappa \mathrm{B})$ and $\mathrm{ul}-$ timately to activation of cytokine gene promoters. ${ }^{24,25}$

A family of (currently) ten TLRs has been identified with a wide range of ligand specificity, including bacterial, fungal and yeast proteins. Thus, TLR4 is the LPS receptor, TLR2 is predominantly responsible for recognizing Gram-positive cell-wall structures, TLR5 is the receptor for flagellin and TLR9 recognizes CpG elements in bacterial DNA $25,26,27$.

An additional layer of complexity has been provided by the discovery that there are several additional pathways by which cells recognize microbial components. The triggering receptor expressed on myeloid cells (TREM-1) and the myeloid DAP12-associating lectin (MDL-1) are two recently identified receptors involved in monocytic activation and inflammatory response. TREM-1 is upregulated in the presence of various microorganisms, although its ligand unknown ${ }^{28,29,30}$. Monocytic intracellular proteins NOD1 and NOD2 (for nucleotide-binding oligomerization domain), which seem to have the ability to bind to and confer responsiveness to LPS, were recently described. Genotypic variations in NOD2 might be associated with phenotypic variations in LPS responsiveness. Peptidoglycan-recognition proteins (PGRPs) were identified in moths, and a family of PGRP genes was subsequently found in humans. Different PGRPs can distinguish between Grampositive and Gram-negative bacteria ${ }^{31,32}$.

\section{Signal amplification}

Following the initial host-microbial interaction, there is widespread activation of the innate immune response, which coordinates a defensive response involving both humoral and cellular components ${ }^{33}$. Mononuclear cells release the classic pro-inflammatory cytokines IL-1, IL-6 and TNF$\alpha$, but in addition, an array of other cytokines, including IL-12, IL-15 and IL-18, and a host of other small molecules are released. TNF- $\alpha$ and IL-1 are the prototypic inflammatory cytokines that mediate many of the immunopathological features of LPS-induced shock. They are released during the first 30-90 minutes after exposure toLPS, activate a second level of inflammatory cascades in turn, including cytokines, lipid mediators and reactive oxygen species and up-regulate cell adhesion molecules, which initiates inflammatory cell migration into tissues. ${ }^{34,35}$.

One of the most intriguing concepts related to host recognition and signal amplification after a challenge with microbes is tolerance. Exposure of macrophages to LPS or other proinflammatory stimuli, such as cytokine TNF- $\alpha$, can induce a state of tolerance, in which reduced activation is found upon subsequent exposure to LPS or the proinflammatory mediator. Among the proposed mechanisms, reduced TLR expression has been speculated. Brunialti et al. ${ }^{36}$ have elegantly demonstrated that the expression of TLRs 2 and 4 in monocytes from septic patients is preserved, although they found a lower production of cytokines after inflammatory stimuli. These findings suggest that the down-regulation observed in patients with severe sepsis and septic shock appears to be related to intracellular pathways and not due to TLR expression. Indirect evidence from the authors had already demonstrated this, using biotinylated LPS and flow cytometry to study LPSmonocyte interaction and LPS-induced cellular activation in whole blood from septic patients ${ }^{37}$. Furthermore, the same group ${ }^{38}$ has demonstrated that neutrophils from septic patients preserve their capacity for phagocytosis and generate reactive oxygen species. Taken together, these findings suggest that tolerance is a phenomenon linked to macrophage response and is not related to TLR expression.

More recently, a novel cytokine has been extensively evaluated. High mobility group B1 (HMGB1) has been identified as a cytokine-like product of macrophages that appears much later after LPS stimulation. It stabilizes nucleosomes, facilitates gene transcription and modulates the activity of steroid hormone receptors ${ }^{39}$. Subsequently, patients with sepsis have elevated serum levels of HMGB1, and higher levels, in some studies are associated with an increased mortality, suggesting that clinical intervention by blocking or neutralizing HMGB1 might be a viable treatment option ${ }^{41,42}$. Recently, we have shown that neutrophils from volunteers and septic patients show a different pattern of gene expression after culture with HMGB1. How- 
ever, neutrophils from septic patients preserve intracellular activation and express proinflammatory genes, suggesting that neutrophils are not anergic or tolerant, in contrast to macrophages ${ }^{42}$. These data are in agreement with those mentioned before.

Another macrophage-derived cytokine that has been identified as a potential therapeutic target in sepsis is macrophage migration inhibitory factor (MIF). It mediates shock caused by Gram-positive and Gram-negative bacteria. MIF has a curious relationship with glucocorticoids, which are normally thought of as being anti-inflammatory, because low doses of glucocorticoids paradoxically induce macrophage MIF. Once released, MIF then acts as a proinflammatory agent, overriding the ability of glucocorticoids to prevent shock in animal models of sep$\operatorname{sis}^{43,44,45}$.

\section{Neutrophil migration}

Neutrophils have a dual role in sepsis. On one hand, these cells are crucial for local control of bacterial growth and, consequently, for the prevention of bacterial dissemination. On the other hand, neutrophils play an important role in the endothelial activation and organ failure development. Cunha's group has advocated that impaired neutrophil migration to the infectious focus is associated with high mortality and increased numbers of bacteria in peritoneal exudate and blood in a cecal-ligation and puncture CLP model in rats. Conversely, in sublethal sepsis, neutrophil migration was not suppressed, and the bacterial infection was restricted to the peritoneal cavity; consequently, no significant mortality was observed. This group has also addressed the mechanisms of neutrophil migration impairment. They have demonstrated that the nitric oxide pathway $^{46}$ and TLR signaling ${ }^{47}$ are both involved in this process.

\section{The coagulation cascade}

Cytokines are also important in inducing a procoagulant effect in sepsis. Coagulation disorders are common in sepsis, and $30-50 \%$ of patients have the more severe clinical form, disseminated intravascular coagulation. Coagulation pathways are initiated by LPS and other microbial components, inducing expression of tissue factor in mononuclear and endothelial cells. Tissue factor activates a series of proteolytic cascades that result in the conversion of prothrombin to thrombin, which in turn generates fibrin from fibrinogen. Simultaneously, normal regulatory fibrinolytic mechanisms (fibrin breakdown by plasmin) are impaired because of high plasma levels of plasminogen-activator in- hibitor type-1 (PAI-1) that prevent generating plasmin from the precursor plasminogen. The net result is enhanced production and reduced removal of fibrin, leading to the deposition of fibrin clots in small blood vessels, impairing tissue perfusion and organ function. Proinflammatory cytokines, in particular IL-1 and IL-6, are powerful inducers of coagulation; conversely, IL-10 regulates coagulation by inhibiting the expression of tissue factor in monocytes. An additional cause of the procoagulant state in sepsis is the down-regulation of three naturally occurring anticoagulant proteins: antithrombin, protein $\mathrm{C}$ and tissue factor pathway inhibitor ${ }^{48,49}, 50$. These natural anticoagulants are of particular interest because they have anti-inflammatory properties in addition to their effect on thrombin generation. These effects include the release of monocyte-derived TNF$\alpha$ by inhibiting activation of the transcription factors NF$\kappa \mathrm{B}$ and activator protein (AP)-1. Particular attention has focused on Protein $\mathrm{C}$, which is converted to the activated form (aPC) when thrombin complexes with thrombomodulin, an endothelial transmembrane glycoprotein. Once aPC is formed, it dissociates from an endothelial protein $\mathrm{C}$ receptor (EPCR) before binding protein $\mathrm{S}$, resulting in inactivation of factors Va and VIIIa and, thus, blockade of the coagulation cascade. It has been shown recently that aPC uses EPCR as a co-receptor for cleavage of proteaseactivated receptor 1 (PAR1). Gene profiling showed that PAR1 signaling could account for the activation of aPCinduced protective genes, including the immunomodulatory monocyte chemoattractant protein-1 (MCP-1), which suggests a role for PAR-1 activation in protection from sepsis. In septic patients, aPC levels are reduced, and expression of endothelial thrombomodulin and EPCR are impaired, providing some support for the notion that replacement of aPC might have therapeutic value ${ }^{51,52}$.

\section{The counter-inflammatory response}

The profound proinflammatory response that occurs in sepsis is balanced by an array of counter-regulatory molecules that attempt to restore immunological equilibrium. Counter-inflammatory cytokines include antagonists such as the soluble TNF receptors and IL-1 receptor antagonist, decoy receptors such as IL-1 receptor type II, inactivators of the complement cascade and anti-inflammatory cytokines, of which IL-10 is the prototype. In concert with this, the host response to injury includes profound changes in metabolic activity (increased cortisol production and release of catecholamines), induction of acute-phase proteins and endothelial activation with upregulation of adhesion molecules and release of prostanoids and platelet-activating factor (PAF). Another facet of down-regulation of immunity that 
occurs in sepsis is the development of lymphocyte apoptosis; subset analysis of autopsy tissue samples has shown that there is selective depletion of B and $\mathrm{CD}^{+}$lymphocytes. This process and its functional consequences are viewed as part of a more general state of immunosuppression, characterized by T-cell hypo-responsiveness and anergy, which occurs to some extent in most septic patients and is seen as a counter-balancing response (and sometimes, over-response) to the initial proinflammatory state. It is because of this overresponse that some investigators view the counter-inflammatory response as the cause of an inadequate host defense against infection and thus as a potential 'mediator' of sepsis and progressive organ failure. Several researchers have pursued the notion that reversal of this immunosuppressive state might be of therapeutic value. For instance, mice transfected with the human gene $b c l-2$, which overexpresses the antiapoptotic protein $\mathrm{Bcl}-2$, are protected from death after caecal ligation and puncture, and patients that received IFN- $\gamma$ in a small, nonrandomized clinical study showed up-regulation of HLA-DR in their monocytes and a better-than-anticipated survival. ${ }^{53}$

\section{Mechanisms of organ failure}

The ultimate cause of death in patients with sepsis is multiple organ failure. There is a close relationship between the severity of organ dysfunction on admission to an ICU and the probability of survival and between the numbers of organs failing and the risk of death. The mechanisms involve widespread fibrin deposition that causes microvascular occlusion, the development of tissue exudates that further compromise adequate oxygenation and disorders of microvascular homeostasis that result from the elaboration of vasoactive substances such as PAF, histamine and prostanoids. Cellular infiltrates, particularly neutrophils, damage tissue directly by releasing lysosomal enzymes and superoxide-derived free radicals. TNF- $\alpha$ and other cytokines increase the expression of inducible nitric oxide synthase, and increased production of nitric oxide causes further vascular instability and may also contribute to the direct myocardial depression that occurs in sepsis. ${ }^{54,55,56}$ The tissue hypoxia that develops in sepsis is reflected in the oxygen debt, i.e., the difference between oxygen delivery and oxygen requirements. The extent of the oxygen debt is related to the outcome from sepsis, and strategies designed to optimize oxygen delivery to the tissues can improve survival ${ }^{57}$. In addition to hypoxia, cells may be dysoxic; i.e., unable to properly utilize available oxygen. Recent data suggest that this may be another consequence of excess nitric oxide production because skeletal muscle biopsies from septic patients show evidence of impaired mitochondrial respiration, which is inhibited by nitric oxide ${ }^{58,59}$. Cross-talk between cytokines and neurohormones is the cornerstone of restoration of homoeostasis during stress. Production and release of vasopressin and corticotropin-releasing hormone are enhanced by circulating TNF and interleukins-1, -6 and -2 , by locally expressed interleukin 1 and NO and by afferent vagal fibers. Moreover, cortisol synthesis is modulated by locally expressed interleukin- 6 and TNF- $\alpha$. Up-regulated hormones help maintain cardiovascular homoeostasis and cellular metabolism and contain foci of inflammation. Impaired endocrine responses to sepsis might result from cytokines, neuronal apoptosis, metabolic and ischemic derangements in the hypothalamic-pituitary and adrenal glands or drug administration. Deficiencies in adrenal gland function and vasopressin production occur in about a half and a third of septic shock cases, respectively, and contribute to hypotension and death. Other endocrine disorders during sepsis have unclear mechanisms and consequences ${ }^{60,61}$.

\section{Genetic polymorphisms}

Among this vast array of host molecules that orchestrate the response to sepsis, there are many examples of genetic variability that influence physiological activity. Various genetic polymorphisms are associated with increased susceptibility to infection and poor outcomes. Markers of susceptibility could include single nucleotide polymorphisms of genes encoding cytokines (e.g., TNF, lymphotoxin- $\alpha$, interleukin-10, interleukin-18, interleukin1 receptor antagonist, interleukin 6 and interferon $\alpha$ ), cell surface receptors (e.g., CD14, MD2, toll-like receptors 2 and 4 and Fc-gamma receptors II and III), lipopolysaccharide ligand (lipopolysaccharide binding protein, bactericidal permeability increasing protein), mannose-binding lectin, heat shock protein 70, angiotensin I-converting enzyme, plasminogen activator inhibitor and caspase-12. Use of genotype combinations could improve the identification of high-risk groups ${ }^{62,63,64,65}$.

\section{THERAPEUTIC APPROACHES}

Despite the extraordinary developments in understanding the immunopathology of sepsis, therapeutic advances have been painfully slow. Septic shock remains a major source of both short- and long-term morbidity and mortality and places a large burden on the healthcare system ${ }^{66}$. The recent identification of molecules in humans that sense microbial determinants has been an important step in understanding the molecular and cellular basis of sepsis. Characterizing the links between inflammation, coagulation and the immune and neuroendocrine systems has led to the de- 
Table 3 - Severe Sepsis Bundles

\section{Sepsis Resuscitation Bundle}

(To be accomplished as soon as possible and scored over the first 6 hours):

1. Measure serum lactate.

2. Obtain blood cultures prior to antibiotic administration.

3. From the time of presentation, administer broad-spectrum antibiotics within 3 hours for ED admissions and 1 hour for non-ED ICU admissions

4. In the event of hypotension and/or lactate $>36 \mathrm{mg} / \mathrm{dL}$ :

a) Deliver an initial minimum of $20 \mathrm{~mL} / \mathrm{kg}$ of crystalloid (or colloid equivalent).

b) Apply vasopressors for hypotension that does not respond to initial fluid resuscitation to maintain mean arterial pressure (MAP) $>65 \mathrm{~mm}$ $\mathrm{Hg}$.

5. In the event of persistent hypotension despite fluid resuscitation (septic shock) and/or lactate $>4 \mathrm{mmol} / \mathrm{L}(36 \mathrm{mg} / \mathrm{dL})$ :

a) Achieve central venous pressure (CVP) of $>8-12 \mathrm{mmHg}$.

b) Achieve central venous oxygen saturation $\left(\mathrm{ScvO}_{2}\right)$ of $>70 \%$.

Sepsis Management Bundle

(To be accomplished as soon as possible and scored over the first 24 hours):

1. Administer low-dose steroids for septic shock in accordance with a standardized ICU policy.

2. Administer drotrecogin alfa (activated) in accordance with a standardized ICU policy.

3. Glucose control maintained above lower limit of normal, but $<150 \mathrm{mg}$ / dl.

4. Maintain inspiratory plateau pressures at $<30 \mathrm{~cm} \mathrm{H}_{2} \mathrm{O}$ for mechanically ventilated patients.

velopment of international guidelines. New knowledge about apoptosis, leukocyte reprogramming, epithelial dysfunction and factors involved in sepsis holds promise for the development of new therapeutic approaches. A group of international critical care and infectious disease clinicians, experts in the diagnosis and management of infection and sepsis who represent 11 organizations, came together to develop guidelines that the bedside clinician could use to improve outcome in severe sepsis and septic shock. This process represented phase II of the Surviving Sepsis Campaign, an international effort to increase awareness and improve outcomes in severe sepsis ${ }^{67}$.

Besides guidelines, the Severe Sepsis Bundles are designed to allow teams to follow the timing, sequence and goals of the individual elements of care in order to achieve the goal of a $25 \%$ reduction in mortality from severe sepsis (Table 3). Individual hospitals should use the bundles to create customized protocols and pathways specific to their institutions. However, all of the elements in the bundles must be incorporated in these protocols. The addition of other strategies not found in the bundles is not recommended. The bundle will form the basis for the measurements that improvement teams will conduct to follow hospitals' progress as they make changes. Hospitals should implement two different Severe Sepsis Bundles. Each bundle articulates requirements for specific timeframes.

- Sepsis Resuscitation Bundle: Tasks that should begin immediately but must be done within 6 hours for pa- tients with severe sepsis or septic shock.

- Sepsis Management Bundle: Tasks that should begin immediately but must be done within 24 hours for patients with severe sepsis or septic shock. ${ }^{67,68}$

\section{Initial Resuscitation}

The resuscitation of a patient with severe sepsis or sepsis-induced tissue hypoperfusion should begin as soon as the syndrome is recognized. An elevated serum lactate concentration identifies tissue hypoperfusion in patients at risk who are not hypotensive. During the first $6 \mathrm{hrs}$ of resuscitation, the goals of initial resuscitation of sepsis-induced hypoperfusion should include all of the following as one part of a treatment protocol:

Central venous pressure (CVP): 8-12 mm Hg,

Mean arterial pressure (MAP): $\geq 65 \mathrm{~mm} \mathrm{Hg}$,

Urine output: $\geq 0.5 \mathrm{~mL} \cdot \mathrm{kg}^{-1} \cdot \mathrm{hr}^{-1}$ and

Central venous (superior vena cava) or mixed venous oxygen saturation: $\geq 70 \%{ }^{68,69}$.

Predictive factors of fluid responsiveness have been evaluated in order to select patients who might benefit from volume expansion and avoid ineffective or even deleterious volume expansion. There is a minimal value of static ventricular preload parameters, and the use of dynamic parameters in the decision-making process is more effective concerning volume expansion. In sedated patients receiving mechanical ventilation in a volume-controlled mode with a tidal volume of at least $8 \mathrm{ml} / \mathrm{kg}$ with acute circulatory failure related to sepsis, the use of pulse pressure variation is an accurate indicator of fluid responsiveness ${ }^{70}$.

\section{Diagnosis}

Appropriate cultures should always be obtained before antimicrobial therapy is initiated. Two blood cultures should be obtained, with at least one drawn percutaneously and one drawn through each vascular access device, unless the device was recently ( $<48$ hrs) inserted. Cultures from other sites should be obtained before antibiotic therapy is initiated as the clinical situation dictates ${ }^{71,72,73}$.

\section{Antibiotic Therapy}

Intravenous antibiotic therapy should be started within the first hour (and should be reasonable until the third hour) that severe sepsis is recognized, after appropriate cultures have been obtained. Establishing a supply of premixed antibiotics is an appropriate strategy to enhance the likelihood that antimicrobial agents will be infused promptly. The initial selection of an empirical antimicrobial regimen 
should be sufficiently broad; there is ample evidence that failure to initiate appropriate therapy promptly has adverse consequences on outcome. All patients should receive an initial full loading dose of each antimicrobial. De-escalation antibiotic therapy should be tailored according to clinical status, severity of illness and culture results ${ }^{73,74,75}$.

\section{Source Control}

Every patient presenting with severe sepsis should be evaluated for the presence of a focus on infection amenable to source control measures; specifically, the drainage of an abscess or local focus of infection, the debridement of infected necrotic tissue, the removal of a potentially infected device or the definitive control of a source of ongoing microbial contamination ${ }^{76,77}$.

\section{Fluid Therapy}

Fluid resuscitation may consist of natural or artificial colloids or crystalloids. There is no evidence-based support for one type of fluid over another. As the volume of distribution is much larger for crystalloids than for colloids, resuscitation with colloids requires less fluid to achieve the same end points. Fluid challenge in patients with suspected hypovolemia may be given at a rate of 500-1000 mL of crystalloids or $300-500 \mathrm{~mL}$ of colloids over $30 \mathrm{~min}$ and repeated on the basis of response (e.g., increase in blood pressure and urine output) and tolerance (e.g., evidence of intravascular volume overload $)^{78,79,80}$.

In animal models, ethyl pyruvate (EP) reduces organ system damage in ischemia/reperfusion injury and hemorrhagic and endotoxic shock, at least in part through its antioxidant action. In addition, EP appears to have direct beneficial effects on cytokine expression and proinflammatory gene regulation. These findings could be a rationale for the use of EP in septic patients; however, more studies are needed to support its use $\mathrm{e}^{81}$.

Our group has tested the hypothesis that a hypertonic solution could be an alternative solution for sepsis. In a previous study, we found that an early, large volume of crystalloid after live Escherichia coli injection in dogs promoted partial and transient benefits during the fluid infusion, which were especially poor at the splanchnic bed ${ }^{82,83}$. Subsequently, we have tested the hypothesis that hypertonic solution (HS) infusion promotes better systemic and regional benefits than conventional isotonic crystalloid infusion in experimental sepsis (infusion of $E$. coli at a dose of $1.2 \times 10^{10} \mathrm{cfu} / \mathrm{kg}$ ). A large volume of Lactated Ringer's solution or a small volume of HS promoted similar transient hemodynamic benefits that were unable to restore sepsis-induced perfusional deficits. However, a single bolus of HS did promote sustained systemic and mesenteric oxygen extraction reductions without deterioration of perfusional markers such as lactate levels and $\mathrm{pCO}_{2}$ gradients ${ }^{84}$. A clinical trial should be carried out to validate these findings.

\section{Vasopressors}

When an appropriate fluid challenge fails to restore adequate blood pressure and organ perfusion, therapy with vasopressor agents should be started. Use of an arterial catheter provides a more accurate and reproducible measurement of arterial pressure. Either norepinephrine or dopamine (through a central catheter as soon as available) is the first-choice vasopressor agent for correcting hypotension in septic patients. Low-dose dopamine should not be used for renal protection as part of the treatment of severe sepsis. Vasopressin use may be considered in patients with refractory shock despite adequate fluid resuscitation and high-dose conventional vasopressors. It should be administered at infusion rates of $0.01-0.04$ units $/ \mathrm{min}^{85,86}$.

\section{Inotropic Therapy}

In patients with low cardiac output despite adequate fluid resuscitation, dobutamine may be used to increase cardiac output. If used in the presence of low blood pressure, it should be combined with vasopressor therapy. A strategy of increasing cardiac index to achieve an arbitrarily predefined elevated level is not recommended ${ }^{87}$.

\section{Steroids}

Intravenous corticosteroids (e.g., hydrocortisone, 200$300 \mathrm{mg} /$ day for 7 days in three or four divided doses or by continuous infusion) are suggested in patients with septic shock who respond poorly to both fluid replacement and vasopressors. Some experts would use a $250 \mu \mathrm{g}$ adrenocorticotropic hormone ACTH stimulation test to identify responders (i.e., $>9 \mu \mathrm{g} / \mathrm{dL}$ increase in plasmatic cortisol 30 $60 \mathrm{~min}$ post-ACTH administration) and discontinue therapy in these patients ${ }^{88}$. However, in a recent trial (CORTICUS), the ACTH test was not able to discriminate patients who will eventually respond to steroid treatment. Hence, this test has been discouraged. Because hydrocortisone has intrinsic mineralocorticoid activity, there is controversy as to whether fludrocortisone should be added.

A post hoc analysis of the effect of treatment with low doses of hydrocortisone and fludrocortisone on mortality in patients with septic shock showed that a 7-day treatment with low doses of corticosteroids was associated with bet- 
ter outcomes in septic shock-associated early ARDS nonresponders but not in responders or in septic shock patients without $\operatorname{ARDS}^{89,90,91}$.

\section{Recombinant Human Activated Protein C (rhAPC)}

Using rhAPC is suggested in patients at high risk of death (e.g., APACHE II $\geq 25$, sepsis-induced multiple organ failure, septic shock) and with no absolute contraindication related to bleeding risk or relative contraindication that outweighs the potential benefit of rhAPC. The ENHANCE study has shown that patients treated within 0-24 hrs from their first sepsis-induced organ dysfunction had a lower observed mortality rate than those treated after 24 hrs. The ADDRESS study indicated that rhAPC should not be used in patients with severe sepsis who are at a low risk for death, such as those with single-organ failure or an APACHE II score less than 25. In these patients, there was an absence of a beneficial treatment effect, coupled with an increased incidence of serious bleeding. ${ }^{92,}{ }^{93}$ More recently, a new industry-funded randomized clinical trial has been prepared to test the efficacy of rhAPC infusion only in high-risk septic patients.

\section{Mechanical Ventilation of Sepsis-Induced Acute Lung Injury (ALI)/ARDS}

High tidal volumes that are coupled with high plateau pressures should be avoided in ALI and/or ARDS; the goal is a reduction in tidal volumes over 1-2 hrs to a "low" tidal volume (i.e., $6 \mathrm{~mL}$ per kilogram of predicted body weight) in conjunction with end-inspiratory plateau pressures $<30$ $\mathrm{cmH}_{2} \mathrm{O}$. Hypercapnia can be tolerated in order to minimize plateau pressures and tidal volumes. The use of hypercarbia is limited in patients with preexisting metabolic acidosis and is contraindicated in patients with increased intracranial pressure. A minimum amount of positive end-expiratory pressure should be set to prevent lung collapse at end-expiration. Setting positive end-expiratory pressure based on the severity of the oxygenation deficit and guided by the $\mathrm{FiO}_{2}$ required to maintain adequate oxygenation is one acceptable approach. Some experts titrate positive end-expiratory pressure according to bedside measurements of thoracopulmonary compliance in order to obtain the highest compliance, reflecting lung recruitment $^{94,95,96,97}$. One trial has shown that, in patients with ALI and ARDS who receive mechanical ventilation with a tidal-volume goal of $6 \mathrm{~mL}$ per kilogram of predicted body weight and an end-inspiratory plateau-pressure limit of $30 \mathrm{~cm}$ of water, clinical outcomes are similar whether lower or higher positive end expiratory pressure (PEEP) levels are used ${ }^{98}$. The currently suggested strategy of ventilation with low lung vol- umes can aggravate lung collapse and potentially produce lung injury through shear stress at the interface between aerated and collapsed lung, as a result of repetitive opening and closing of alveoli. An 'open lung strategy' focused on alveolar patency has therefore been recommended. In animal studies, recruitment maneuvers clearly reverse the derecruitment associated with low tidal volume ventilation, improve gas exchange and reduce lung injury. Data regarding the use of recruitment maneuvers in patients with ARDS show mixed results, with increased efficacy in those with a short duration of ARDS, good chest wall compliance, and extrapulmonary ARDS. More data are needed to support this strategy ${ }^{102,103}$.

In experienced facilities, prone positioning should be considered in ARDS patients who require potentially injurious levels of $\mathrm{FiO}_{2}$ or plateau pressure who are not at high risk for adverse consequences of positional changes ${ }^{100}$.

A weaning protocol should be in place, and mechanically ventilated patients should undergo a spontaneous breathing trial to evaluate their ability to discontinue mechanical ventilation when they satisfy the following criteria: a) arousable; b) hemodynamically stable (without vasopressor agents); c) no new potentially serious conditions; d) low ventilatory and end-expiratory pressure requirements; and e) requiring levels of $\mathrm{FiO}_{2}$ that could be safely delivered with a face mask or nasal cannula. If the spontaneous breathing trial is successful, extubation should be considered $^{101,102,103}$.

\section{Glucose Control}

Following initial stabilization of patients with severe sepsis, blood glucose should be maintained at $<150 \mathrm{mg} /$ dL. Studies supporting the role of glycemic control have used continuous infusion of insulin and glucose. With this protocol, glucose should be monitored frequently after initiation of the protocol (every 30-60 $\mathrm{min}$ ) and on a regular basis (every $4 \mathrm{hrs}$ ) once the blood glucose concentration has stabilized. A large single-center trial of postoperative surgical patients showed significant improvement in survival when continuous-infusion insulin was used to maintain glucose between 80 and $110 \mathrm{mg} / \mathrm{dL}^{104}$. Another trial in a medical ICU showed that intensive insulin therapy significantly reduced morbidity but not mortality. Although the risk of subsequent death and disease was reduced in patients treated for three or more days, these patients could not be identified before therapy ${ }^{105,106}$.

\section{CONCLUSION}

Sepsis syndromes are still a daily challenge for intensivists all over the world. Despite great improvements 
in the understanding of epidemiology, pathophysiology and genetic predisposition to sepsis, both morbidity and mortality associated with severe sepsis and septic shock remain unacceptably high. Recent efforts aiming to provide a framework of uniform definitions and terms have been performed in order to facilitate communication, research and patient care. There has been progress in clinical management based on widely known guidelines, and interventions targeting specific pathologic pathways have led to important breakthroughs, as well as some deceptions. In the future, we hope that it will be possible to tailor treatment strategies based on knowledge of an individual's genetic profile, comorbidities and phenotypic expressions derived from environmental influences and host-pathogen interactions.

\section{REFERENCES}

1. Balk RA. Severe sepsis and septic shock: definitions, epidemiology, and clinical manifestations. Crit Care Clin. 2000;16:179-92.

2. Vincent JL, Abraham E. The last 100 years of sepsis. Am J Resp Crit Care Med. 2006;173:256-263.

3. Rivers EP, McIntyre L, Morro DC, Rivers K. Early and innovative interventions for severe sepsis and septic shock: taking advantage of a window of opportunity. CMAJ. 2005;173:1054-65.

4. American College of Chest Physicians/Society of Critical Care Medicine. Consensus Conference: Definitions for sepsis and organ failure and guidelines for the use of innovative therapies in sepsis. Crit Care Med. 1992;20:864.

5. Levy MM, Fink MP, Marshall JC, Abraham E, Angus D, Cook D, et al. 2001 SCCM/ESICM/ACCP/ATS/SIS International Sepsis Definitions Conference. Crit Care Med. 2003;31:1250.

6. Rangel-Frausto MS, Pittet D, Costigan M, Hwang T, Davis CS, Wenzel RP. The natural history of the systemic inflammatory response syndrome (SIRS). A prospective study. JAMA. 1995;273:117.

7. Chandra A, Enkhbaatar P, Nakano Y, Traber LD, Traber DL. Sepsis: emerging role of nitric oxide and selectins. Clinics. 2006;61:71-76.

8. Angus D, Pereira CAP, Silva E. Epidemiology of severe sepsis around the world. Curr Drug Targets Immune Endocr Metabol. 2006;6:7-16.

9. Angus DC, Linde-Zwirble WT, Lidicker J, Clermont G, Carcillo J, Pinsky MR. Epidemiology of severe sepsis in the United States: analysis of incidence, outcome, and associated cost of care. Crit Care Med. 2001;29:1303-10.

10. Balk RA. Optimum treatment of severe sepsis and septic shock: evidence in support of the recommendations. Dis Mon. 2004;50:163213.

11. Silva E, Pedro M de A, Sogayar AC, Mohovic T, Silva CL, Janiszewski M, et al. Brazilian Sepsis Epidemiological Study (BASES study). Crit Care. 2004;8:R251-260.

12. Quartin AA, Schein RM, Kett DH, Peduzzi PN. Magnitude and duration of the effect of sepsis on survival. JAMA. 1997;277:1058.

13. Martin GS, Mannino DM, Eaton S, Moss M. The epidemiology of sepsis in the United States from 1979 through 2000. N Engl J Med. 2003;348:1546.

14. Annane D, Aegerter P, Jars-Guincestre MC, Guidet B. Current Epidemiology of Septic Shock: the CUB-Rea Network. Am J Respir Crit Care Med. 2003;168:165.

15. Friedman G, Silva E, Vincent JL. Has the mortality of septic shock changed with time? Crit Care Med. 1998;26:2078-86.

16. Brun-Buisson C, Doyon F, Carlet J. Bacteremia and severe sepsis in adults: a multicenter prospective survey in ICUs and wards of 24 hospitals. Am J Respir Crit Care Med. 1996;154:617-24.

17. Vincent JL, Sakr Y, Sprung CL, Ranieri VM, Reinhart K, Gerlach H, et al. Sepsis in european intensive care units: results of the SOAP study. Crit Care Med (in press).
18. Janeway CA Jr., Medzhitov R. Introduction: the role of innate immunity in the adaptive immune response. Semin Immuno. 1998; 10:349-50.

19. Bernard GR, Vincent JL, Laterre PF, LaRosa SP, Dhainaut JF, LopezRodriguez A, et al. Efficacy and safety of recombinant human activated protein C for severe sepsis. N Engl J Med. 2001;344:699-709.

20. Seydel U, Oikawa M, Fukase K, Kusumoto S, Brandenburg K. Intrinsic conformation of lipid $\mathrm{A}$ is responsible for agonistic and antagonistic activity. Eur J Biochem. 2000;267:3032-9.

21. Majcherczyk PA, Langen H, Heumann D, Fountoulakis M, Glauser MP, Moreillon P. Digestion of Streptococcus pneumoniae cell walls with its major peptidoglycan hydrolase releases branched stem peptides carrying proinflammatory activity. Biol Chem. 1999;274:12537-43.

22. Morath S, Geyer A, Hartung T. Structure-function relationship of cytokine induction by lipoteichoic acid from Staphylococcus aureus. J Exp Med. 2001;193:393-7.

23. Lavoie PM, Thibodeau J, Erard F, Sekaly RP. Understanding the mechanism of action of bacterial superantigens from a decade of research. Immunol Rev. 1999;168:257-69.

24. Wright SD, Ramos RA, Tobias PS, Ulevitch RJ, Mathison JC. CD14, a receptor for complexes of lipopolysaccharide (LPS) and LPS binding protein. Science. 1990;249:1431-3.

25. Aderem A, Ulevitch RJ. Toll-like receptors in the induction of the innate immune response. Nature. 2000;406:782-7.

26. Vasselon T, Detmers P. A. Toll receptors: a central element in innate immune responses. Infect Immun. 2002;70:1033.

27. Opal SM, Huber CH. Bench-to-bedside review: toll-like receptors and their role in septic shock. Crit Care. 2002;6:125-36.

28. Liu C, Xu Z, Gupta D, Dziarski R. Peptidoglycan recognition proteins: a novel family of four human innate immunity pattern recognition molecules. J Biol Chem. 2001;276:34686-94.

29. Bouchon A, Dietrich J, Colonna M. Inflammatory responses can be triggered by TREM-1, a novel receptor expressed on neutrophils and monocytes. J Immunol. 2000;164:4991-5.

30. Bouchon A, Facchetti F, Weigand MA, Colonna M. TREM-1 amplifies inflammation and is a crucial mediator of septic shock. Nature. 2001;410:1103-7.

31. Inohara N, Ogura Y, Chen FF, Muto A, Nunez G. Human Nod1 confers responsiveness to bacterial lipopolysaccharides. J Biol Chem. $2001 ; 276: 2551-4$

32. Inohara N, Ogura Y, Nunez G. Nods: a family of cytosolic proteins that regulate the host response to pathogens. Curr Opin Microbiol. 2002;5:76-80

33. Martins PS, Brunialti MK, da Luz Fernandes M, Martos LS, Gomes $\mathrm{NE}$, Rigato $\mathrm{O}$, et al. Bacterial recognition and induced cell activation in sepsis. Endocr Metab Immune Disord Drug Targets. 2006;6:18391. 
34. Dinarello CA. Proinflammatory and anti-inflammatory cytokines as mediators in the pathogenesis of septic shock. Chest. 1997;112:321S9S.

35. Cohen J. Adjunctive therapy in sepsis: a critical analysis of the clinical trial program. Br Med Bull. 1999;55:212-26.

36. Brunialti MK, Martins PS, Barbosa de Carvalho H, Machado FR Barbosa LM, Salomao R. TLR2, TLR4, CD14, CD11B, and CD11C expressions on monocytes surface and cytokine production in patients with sepsis, severe sepsis, and septic shock. Shock. 2006;25:351-7.

37. Salomao R, Brunialti MK, Kallás EG, Martins PS, Rigato O, Freudenberg M. Lipopolysaccharide-cell interaction and induced cellular activation in whole blood of septic patients. J Endotoxin Res. 2002;8:371-9.

38. Martins PS, Kallas EG, Neto MC, Dalboni MA, Blecher S, Salomão $R$. Upregulation of reactive oxygen species generation and phagocytosis, and increased apoptosis in human neutrophils during severe sepsis and septic shock. Shock. 2003;20:208-12.

39. Ulloa M, Messmer D. High-mobility group box 1 (HMGB1) protein friend and foe. Cytokine \& Growth Factor Reviews. 2006;17:189201

40. Yang H, Wang H, Tracey KJ. HMG-1 rediscovered as a cytokine. Shock. 2001;15:247-53.

41. Wang H, Bloom O, Zhang M, Vishnubhakat JM, Ombrellino M, Che J, et al. HMG-1 as a late mediator of endotoxin lethality in mice. Science. 1999;285:248-51.

42. Silva E, Arcaroli J, He Q, Svetkauskaite D, Coldren C, Nick JA, et al HMGB1 and LPS induce distinct patterns of gene expression and activation in neutrophils from patients with sepsis induced acute lung injury. Intensive Care Med. 2007;[Epub ahead of print].

43. Calandra T, Echtenacher B, Roy DL, Pugin J, Metz CN, Hültner L. Protection from septic shock by neutralization of macrophage migration inhibitory factor. Nature Med. 2000;6:164-70.

44. Calandra T, Spiegel LA, Metz CN, Bucala R. Macrophage migration inhibitory factor is a critical mediator of the activation of immune cells by exotoxins of Gram-positive bacteria. Proc Natl Acad Sci USA. $1998 ; 95: 11383-8$

45. Calandra T, Bernhagen J, Metz CN, Spiegel LA, Bacher M, Donnelly $\mathrm{T}$, et al. MIF as a glucocorticoid-induced modulator of cytokine production. Nature. 1995;377:68-71.

46. Benjamin CF, Ferreira SH, Cunha FQ. Role of Nitric Oxide in the Failure of Neutrophil Migration in Sepsis. J Infect Dis. 2000;182:214 23.

47. Alves-Filho JC, Freitas A, Russo M, Cunha FQ. Toll-like receptor 4 signaling leads to neutrophil migration impairment in polymicrobial sepsis. Crit Care Med. 2006;34:461-70.

48. Levi M, ten Cate H. Disseminated intravascular coagulation. N Engl J Med. 1999;341:586-92.

49. Van der Poll T, de Jonge E, Levi M, van Deventer SJ. Pathogenesis of DIC in sepsis. Sepsis. 1999;3:103-10.

50. Okajima K. Regulation of inflammatory responses by natural anticoagulants. Immunol Rev. 2002;184:258-74.

51. Riewald M, Petrovan RJ, Donner A, Mueller BM, Ruf W. Activation of endothelial cell protease activated receptor 1 by the protein $\mathrm{C}$ pathway. Science. 2002;296:1880-2.

52. Faust SN, Levin M, Harrison OB, Goldin RD, Lockhart MS, Kondaveeti $\mathrm{S}$ et al. Dysfunction of endothelial protein $\mathrm{C}$ activation in severe meningococcal sepsis. N Engl J Med. 2001;345:408-16.

53. Rigato O, Silva E, Salomao R. Pathogenesis-Oriented targets for adjunctive therapy. Curr Drug Targets Immune, Endocr Metabol. 2006;6:7-16.
54. Hotchkiss RS, Swanson PE, Freeman BD, Tinsley KW, Cobb JP, Matuschak GM, et al. Apoptotic cell death in patients with sepsis, shock, and multiple organ dysfunction. Crit Care Med. 1999;27:123051

55. Hotchkiss RS, Tinsley KW, Swanson PE, Schmieg RE Jr, Hui JJ, Chang $\mathrm{KC}$, et al. Sepsis-induced apoptosis causes progressive profound depletion of B and CD4+ T lymphocytes in humans. J Immunol. 2001;166:6952-63.

56. Hotchkiss RS, Tinsley KW, Swanson PE, Chang KC, Cobb JP, Buchman TG, et al. Prevention of lymphocyte cell death in sepsis improves survival in mice. Proc Natl Acad Sci USA. 1999;96:145416.

57. Nakagawa NK, Nogueira RA, Correia CJ, Shiwa SR, Costa Cruz JW, Poli de Figueiredo LF. Leukocyte-endothelium interactions after hemorrhagic shock/reperfusion and cecal ligation/puncture: an intravital microscopic study in rat mesentery. Shock. 2006;26:180-6.

58. Döcke WD, Randow F, Syrbe U, Krausch D, Asadullah K, Reinke P, et al. Monocyte deactivation in septic patients: restoration by IFN-g treatment. Nature Med. 1997;3:678-81.

59. Levy MM, Macias WL, Vincent JL, Russell JA, Silva E, Trzaskoma B, et al. Early changes in organ function predict eventual survival in severe sepsis. Crit Care Med. 2005;33:2194-201.

60. Cavaillon JM, Adib-Conquy M, Fitting C, Adrie C, Payen D. Cytokine cascade in sepsis. Scand J Infect Dis. 2003;35:535-44.

61. Singer M, De Santis V, Vitale D, Jeffcoate W. Multiorgan failure is an adaptive, endocrine-mediated, metabolic response to overwhelming systemic inflammation. Lancet. 2004;364:545-8

62. Jaber BL, Rao M, Guo D, Balakrishnan VS, Perianayagam MC, Freeman RB, et al. Cytokine gene promoter polymorphisms and mortality in acute renal failure. Cytokine. 2004;25:212-9.

63. Stuber F. Effects of genomic polymorphisms on the course of sepsis: is there a concept for gene therapy? J Am Soc Nephrol. 2001;12(Suppl. 17):S60-S64.

64. Villar J, Macca-Meyer N, Mendez LP, Flores C. Bench to Bedside Review: Understanding genetic predisposition to sepsis. Crit Care. 2004;8:3.

65. Arcaroli J, Fessler MB, Abraham E. Genetic polymorphisms and sepsis. Shock. 2005;24:300-12.

66. Sogayar AMC, Machado FR, Rea-Neto A. A multicenter, prospective study to evaluate costs of septic patients in Brazilian intensive care units. Pharmacoeconomics. 2007[in press]

67. Silva E, Akamine N, Salomao R, Townsend SR, Dellinger RP, Levy M. Surviving sepsis campaign: a project to change sepsis trajectory. Endocr Metab Immune Disord Drug Targets. 2006;6:217-22.

68. Dellinger RP, Carlet JM, Masur H, Gerlach H, Calandra T, Cohen J, et al. for the Surviving Sepsis Campaign management Guidelines Committee. Surviving Sepsis Campaign guidelines for management of severe sepsis and septic shock. Crit Care Med. 2004;32:858-73.

69. Rivers E, Nguyen B, Havstad S, Ressler J, Muzzin A, Knoblich B, et al.Early goal-directed therapy in the treatment of severe sepsis and septic shock. N Engl J Med. 2001;345:1368-77.

70. Michard F, Teboul JL. Predicting fluid responsiveness in ICU patients: a critical analysis of the evidence. Chest. 2002;121:2000-8.

71. Weinstein MP, Reller LB, Murphy JR, Lichtenstein KA. The clinical significance of positive blood cultures: A comprehensive analysis of 500 episodes of bacteremia and fungemia in adults. I. Laboratory and epidemiologic observations. Rev Infect Dis. 1983;5:35-53.

72. Blot F, Schmidt E, Nitenberg G, Tancrède C, Leclercq B, Laplanche A, et al. Earlier positivity of central venous versus peripheral blood cultures is highly predictive of catheter-related sepsis. J Clin Microbiol. 1998;36:105-9. 
73. Mermel LA, Maki DG. Detection of bacteremia in adults: Consequences of culturing an inadequate volume of blood. Ann Intern Med. 1993;119:270-2.

74. Amsden GW, Ballow CH, Bertino JS. Pharmacokinetics and Pharmacodynamcis of Anti-infective Agents. In: Principles and Practice of Infectious Diseases. Fifth Edition. Mandell GL, Bennett JE, Dolin R (Eds). Philadelphia, Churchill Livingstone, 2000, p. 25361.

75. Hyatt JM, McKinnon PS, Zimmer GS, Schentag JJ. The importance of pharmacokinetic/ pharmacodynamic surrogate markers to outcomes. Focus on antibacterial agents. Clin Pharmacokinet. $1995 ; 28: 143-60$

76. Jimenez MF, Marshall JC. Source control in the management of sepsis. Intensive Care Med. 2001;27:S49-S62.

77. Centers for Disease Control and Prevention. Guidelines for the prevention of intravascular catheter-related infections. MMWR. $2002 ; 51: 1-29$.

78. Choi PT, Yip G, Quinonez LG, Cook DJ. Crystalloids vs. colloids in fluid resuscitation: a systematic review. Crit Care Med. 1999;27:20010.

79. Cook M, Schierhout G, Roberts I. Fluid resuscitation with colloid or crystalloid solutions in critically ill patients: A systematic review of randomized trials. BMJ. 1998;316:961-4.

80. Park M, Azevedo LC, Maciel AT, Pizzo VR, Noritomi DT, da Cruz Neto LM. Evolutive standard base excess and serum lactate level in severe sepsis and septic shock patients resuscitated with early goaldirected therapy: still outcome markers? Clinics. 2006;61:47-52.

81. Fink MP. Ringer's ethyl pyruvate solution: a novel resuscitation fluid for the treatment of hemorrhagic shock and sepsis. Trauma. 2003;54(5 Suppl):S141-3

82. Garrido AG, Poli de Figueiredo LF, Cruz Jr RJ, Silva E, Rocha-eSilva M. Short-lasting systemic and regional benefits of early crystalloid infusion after intravenous inoculation of dogs with live Escherichia coli. Braz J Med Biol Res. 2005;38:873-84.

83. Lagoa CE, De Figueiredo LF, Cruz RJ Jr, Silva E, Rocha-e-Silva M Effects of volume resuscitation on splanchnic perfusion in canine model of severe sepsis induced by live Escherichia coli infusion. Crit Care. 2004;8:R221-228

84. Garrido A del P, Cruz Junior RJ, Poli de Figueiredo LF, Rocha-e-Silva M. Small volume of hypertonic saline as the initial fluid replacement in experimental hypodynamic sepsis. Crit Care. 2006;10:R62.

85. Hollenberg SM, Ahrens TS, Astiz ME. Practice parameters for hemodynamic support of sepsis in adult patients. Crit Care Med. 1999;27:639-60

86. Gattinoni L, Brazzi L, Pelosi P, Latini R, Tognoni G, Pesenti A, et al. A trial of goal-oriented hemodynamic therapy in critically ill patients. SvO2 Collaborative Group. N Engl J Med. 1995;333:1025-32.

87. Hayes MA, Timmins AC, Yau EH, Palazzo M, Hinds CJ, Watson D. Elevation of systemic oxygen delivery in the treatment of critically ill patients. N Engl J Med. 1994;330:1717-22.

88. Annane D, Cavaillon JM. Corticosteroids in sepsis: From bench to bedside? Shock. 2003;20:197-20.

89. Annane D, Sébille V, Charpentier C, Bollaert PE, François B, Korach $\mathrm{JM}$, et al. Effect of treatment with low doses of hydrocortisone and fludrocortisone on mortality in patients with septic shock. JAMA. 2002;288:862-71.

90. Annane D, Sébille V, Bellissant E; Ger-Inf-05 Study Group. Effect of low doses of corticosteroids in septic shock patients with or without early acute respiratory distress syndrome. Crit Care Med. 2006;34:2230 .
91. Meduri GU, Chrousos GP. Effectiveness of prolonged glucocorticoid treatment in acute respiratory distress syndrome: the right drug, the right way? Crit Care Med. 2006;34:236-8.

92. Vincent JL, Bernard GR, Beale R, Doig C, Putensen C, Dhainaut JF, et al. Drotrecogin alfa (activated) treatment in severe sepsis from the global open-label trial ENHANCE: further evidence for survival and safety and implications for early treatment. Crit Care Med. $2005: 33: 2266-77$

93. Abraham E, Laterre PF, Garg R, Levy H, Talwar D, Trzaskoma BL, et al. Drotrecogin alfa (activated) for adults with severe sepsis and a low risk of death. N Engl J Med. 2005;353:1332-41.

94. Amato MB, Barbas CS, Medeiros DM, Magaldi RB, Schettino GP Lorenzi-Filho G, et al. Effect of a protective-ventilation strategy on mortality in the acute respiratory distress syndrome. $\mathrm{N}$ Engl J Med. $1998 ; 338: 347-54$

95. Stewart TE, Meade MO, Cook DJ, Granton JT, Hodder RV, Lapinsky $\mathrm{SE}$, et al. Evaluation of a ventilation strategy to prevent barotrauma in patients at high risk for acute respiratory distress syndrome. Pressureand Volume-Limited Ventilation Strategy Group. N Engl J Med. 1998;338:355-61.

96. Brochard L, Roudot-Thoraval F, Roupie E, Delclaux C, Chastre J, Fernandez-Mondéjar E, et al.Tidal volume reduction for prevention of ventilator-induced lung injury in acute respiratory distress syndrome. The Multicenter Trial Group on Tidal Volume reduction in ARDS. Am J Respir Crit Care Med. 1998;158:1831-8.

97. Brower RG, Shanholtz CB, Fessler HE, Shade DM, White P Jr., Wiene $\mathrm{CM}$, et al. Prospective, randomized, controlled clinical trial comparing traditional versus reduced tidal volume ventilation in acute respiratory distress syndrome patients. Crit Care Med. 1999;27:1492-8.

98. Brower RG, Lanken PN, MacIntyre N, Matthay MA, Morris A, Ancukiewicz M, et al. Higher versus lower positive end-expiratory pressures in patients with the acute respiratory distress syndrome. $\mathrm{N}$ Engl J Med. 2004;351:327-36.

99. Barbas CS, de Matos GF, Pincelli MP, da Rosa Borges E, Antunes T, de Barros JM, et al. Mechanical ventilation in acute respiratory failure: recruitment and high positive end-expiratory pressure are necessary. Curr Opin Crit Care. 2005;11:18-28.

100. Chatte G, Sab JM, Dubois JM, Sirodot M, Gaussorgues P, Robert D.Prone position in mechanically ventilated patients with severe acute respiratory failure. Am J Respir Crit Care Med. 1997;155:473-8.

101. Esteban A, Alía I, Tobin MJ, Gil A, Gordo F, Vallverdú I, et al. Effect of spontaneous breathing trial duration on outcome of attempts to discontinue mechanical ventilation. Spanish Lung Failure Collaborative Group. Am J Respir Crit Care Med. 1999;159:512-8.

102. Ely EW, Baker AM, Dunagan DP, Burke HL, Smith AC, Kelly PT, et al. Effect on the duration of mechanical ventilation of identifying patients capable of breathing spontaneously. N Engl J Med. $1996 ; 335: 1864-9$

103. Esteban A, Alía I, Gordo F, Fernández R, Solsona JF, Vallverdú I, et al. Extubation outcome after spontaneous breathing trials with T-tube or pressure support ventilation. The Spanish Lung Failure Collaborative Group. Am J Respir Crit Care Med. 1997;156:459-65.

104. van den Berghe G, Wouters P, Weekers F, Verwaest C, Bruyninckx F, Schetz M, et al. Intensive insulin therapy in the critically ill patients. N Engl J Med. 2001;345:1359-67.

105. Van den Berghe G, Wilmer A, Hermans G, Meersseman W, Wouters PJ, Milants I, et al. Intensive insulin therapy in the medical ICU. N Engl J Med. 2006;354:449-61.

106. Fowler RA, Annane D. The highs and lows of intensive insulin therapy. Am J Respir Crit Care Med. 2006;173:367-9. 